\title{
Relationship between Membrane Potential and Calcium Ion Fluxes in the Fragmented Sarcoplasmic Reticulum
}

\author{
Makoto Koshita and Ken HotTA \\ Department of Physiology, Nagoya City University \\ Medical School, Nagoya, 467 Japan
}

\begin{abstract}
The relation between membrane potential and $\mathrm{Ca}^{2+}$ fluxes in the skeletal fragmented sarcoplasmic reticulum (FSR) was investigated using cyanine dye (diS- $\left.\mathrm{C}_{3}-(5)\right)$ as a potential probe. Change of membrane potential and $\mathrm{Ca}^{2+}$ release from FSR were induced by changing the ionic composition of the medium.

When the medium was changed from K-gluconate to Tris-gluconate, a large fluorescence intensity change was observed, while no $\mathrm{Ca}^{2+}$ release occurred. On the other hand, when the medium was changed from $\mathrm{K}$-gluconate to $\mathrm{KCl}, \mathrm{Ca}^{2+}$ release occurred notwithstanding a relatively small fluorescence intensity change. This $\mathrm{KCl}$-induced $\mathrm{Ca}^{2+}$ release from FSR was inhibited by the addition of sucrose. Also, the presence of both permeable anion and cation was required for induction of $\mathrm{Ca}^{2+}$ release. These results suggest that there is no correlation between "depolarization" and $\mathrm{Ca}^{2+}$ release.

$\mathrm{Ca}^{2+}$ uptake by FSR created the positive-inside potential which was reversed by the application of $\mathrm{Ca}^{2+}$ ionophore $\mathrm{A} 23187$. The addition of valinomycin or nigericin, and the replacement of $\mathrm{Cl}^{-}$with gluconate affected potential formation. These facts suggest that $\mathrm{Ca}^{2+}$ uptake is accompanied by $\mathrm{K}^{+}$efflux and/or $\mathrm{Cl}^{-}$influx for partial compensation of the change.
\end{abstract}

It is well established that the release of calcium into myoplasm from sarcoplasmic reticulum (SR) triggers the series of reactions leading to contraction of skeletal muscle (CAPUTO, 1978). The idea that depolarization of sarcoplasmic membrane may be an immediate cause of $\mathrm{Ca}^{2+}$ release has been suggested (BASTIAN and NAKAJIMA, 1974; ENDO, 1977). Several works have appeared to support this idea using skinned muscle fibers (ForD and PODOLSKY, 1970; NAKAJIMA and Endo, 1973) and isolated sarcoplasmic reticulum (KASAI and MiYAmoto, 1973, 1976): application of $\mathrm{Cl}^{-}$which supposedly caused depolarization could release $\mathrm{Ca}^{2+}$ stored in SR. However, the evidence that the depolarization actually occurred has been lacking.

Received for publication August 29, 1980

越田 信, 堀田 健 
There were contradictory reports; i.e., MEISSNER and MCKINLEY (1976) and OHNISHI (1979) interpreted that the $\mathrm{Ca}^{2+}$ release from FSR by changing the ionic environment was the osmotic effect rather than depolarization of the SR membrane. Recently, it was demonstrated that inside-negative potential change did not cause $\mathrm{Ca}^{2+}$ release from isolated sarcoplasmic reticulum vesicle (BEELER et al., 1979).

Whether the $\mathrm{Ca}^{2+}$ pump in SR is electrogenic or electroneutral remains uncertain. BEELER et al. (1979) concluded that there was no potential change during $\mathrm{Ca}^{2+}$ uptake by FSR. ÅKERMAN and WolfF (1979) showed positiveinside potential buildup during $\mathrm{Ca}^{2+}$ uptake and suggested partial compensation of charge created by $\mathrm{Ca}^{2+}$ uptake was achieved by $\mathrm{K}^{+}$efflux and/or $\mathrm{Cl}^{-}$influx.

In this paper, it was attempetd to clarify, firstly, the cause of $\mathrm{Ca}^{2+}$ release from FSR by changing the ionic composition of the medium. Secondly, whether or not the membrane potential change is accompanied by $\mathrm{Ca}^{2+}$ uptake, and the role of ions in the medium during $\mathrm{Ca}^{2+}$ fluxes. Gluconate ${ }^{-}$was used as the impermeable anion (Meissner and MCKInLeY, 1976) in the place of $\mathrm{Cl}^{-}$. Tris ${ }^{+}$ and choline ${ }^{+}$are considered as less permeable than $\mathrm{K}^{+}$. For the measurement of membrane potential, a technique of fluorescence dye was employed.

\section{MATERIALS AND METHODS}

Preparation of fragmented sarcoplasmic reticulum (FSR). FSR was prepared from the leg muscle of bullfrog. The muscle was homogenized in $5 \mathrm{~mm}$ PipesTris ( $\mathrm{pH}$ 6.8) for $10 \mathrm{sec} 3$ times. Homogenate was then centrifuged at 4,000 g for $60 \mathrm{~min}$. Supernatant was filtered through 4 layers of gauze and recentrifuged at $8,000 \mathrm{~g}$ for $60 \mathrm{~min}$. Crude FSR, which was obtained as pellets, were suspended in $50 \mathrm{mM} \mathrm{KCl}, 20 \mathrm{~mm}$ Tris-maleate $(\mathrm{pH} 6.8)$ and centrifuged at 5,000 $\mathrm{g}$ for $10 \mathrm{~min}$ to remove actomyosin. Supernatant was centrifuged at $20,000 \mathrm{~g}$ for $60 \mathrm{~min}$ and the pellets, purified FSR, were collected and resuspended in $50 \mathrm{mM} \mathrm{KCl}, 20 \mathrm{~mm}$ Tris-maleate $(\mathrm{pH}$ 6.8) or $0.2 \mathrm{M} \mathrm{K}$-gluconate, $10 \mathrm{~mm}$ Pipes-Tris ( $\mathrm{pH} 7.0)$. All procedures were performed at $4^{\circ} \mathrm{C}$.

Procedure of measurements. Membrane potential change was measured using cyanine dye (diS- $\mathrm{C}_{3}-(5)$ ) as a probe in a Hitachi fluorescence spectrophotometer 204-S. Fluorescence emission was recorded at $660 \mathrm{~nm}$ while excitation was at $620 \mathrm{~nm}$. The expression of fluorescence intensity was arbitrary.

FSR was suspended in $0.2 \mathrm{M} \mathrm{K}$-gluconate, $10 \mathrm{~mm}$ Pipes-Tris ( $\mathrm{pH} 7.0$ ), $1 \mathrm{~mm}$ Mg-gluconate, Twenty $\mu \mathrm{l}$ of FSR $(7.5 \mathrm{mg}$ protein $/ \mathrm{ml})$ was added into $3 \mathrm{ml}$ of $0.2 \mathrm{M}$ various kinds of salt media containing $10 \mathrm{~mm}$ Pipes-Tris (pH 7.0), $1 \mathrm{~mm}$ $\mathrm{Mg}$-gluconate and $2 \mu \mathrm{M}$ dye to achieve the change of ioric environment (final concentration of FSR, $0.05 \mathrm{mg}$ protein $/ \mathrm{ml}$ ).

$\mathrm{Ca}^{2+}$ uptake was started by adding ATP into the reaction medium wherein FSR was suspended. Reaction medium contained $100 \mathrm{~mm} \mathrm{KCl}, 20 \mathrm{~mm}$ Tris- 
maleate ( $\mathrm{pH}$ 6.8), $1 \mathrm{~mm} \mathrm{MgCl}_{2}, 0.1 \mathrm{~mm} \mathrm{CaCl}_{2}, 1 \mathrm{~mm}$ ATP and $0.05 \mathrm{mg}$ FSR protein $/ \mathrm{ml}$, unless otherwise indicated. Aliquots of the assay were filtered on $0.45 \mu \mathrm{m}$ Millipore filters, and $\mathrm{Ca}^{2+}$ in FSR on the filters was determined using a liquid scintillation counter. The amount of $\mathrm{Ca}^{2+}$ in FSR was calculated by subtracting calcium binding of FSR in the absence of ATP from that in its presence. Two $\mu \mathrm{M}$ dye (dissolved in ethanol) was also added when fluorescence intensity was measured. $\mathrm{Ca}^{2+}$ release was initiated by the introduction of $1 \mu \mathrm{M}$ A23187 into the system.

Protein concentration of FSR was determined by the biuret method using bovine serum albumin as a standard.

Reagents. Cyanine dye diS- $\mathrm{C}_{3}$-(5) 3, 3'-dipropyl-2, 2'-thiodicarbocyanine was purchased from Nippon Kankoh Shikiso (Okayama). A23187, $\mathrm{Ca}^{2+}$ ionophore, was obtained from Calbiochem-Behring Corp. $\mathrm{K}^{+}$ionophore valinomycin was a product of P-L Biochemicals, Inc. Nigericin, highly specific agent to increase $\mathrm{K}^{+}$permeability (IwATA and HorIUCHI, 1980), was kindly supplied by Nippon Roche through Professor S. Iwata (Meijo Univ.). Verapamil was a gift from Eisai Co., Ltd. Ethylene glycol bis ( $\beta$-aminoethyl ether)- $N, N, N^{\prime}, N^{\prime}$ tetraacetic acid (EGTA) was purchased from Wako Junyaku. Other reagents were commercial products of analytical grade.

\section{RESULTS}

\section{Fluorescence emission spectra of diS- $C_{3}-(5)$}

The fluorescence dye diS- $\mathrm{C}_{3}-(5)$ was used to follow the change of membrane potential in FSR. The curve (a) in Fig. 1 shows the emission spectrum of diS$\mathrm{C}_{3}-(5)$ in the solution without FSR, and (b)-(h) show that in the presence of various concentrations of FSR. When the concentration of FSR was increased, the fluorescence intensity at $660 \mathrm{~nm}$ decreased and that at $680 \mathrm{~nm}$ increased. These results may indicate that emission at 660 and $680 \mathrm{~nm}$ originated from dye free from and bound to FSR, respectively. The low concentration of FSR (final concentration; $0.05 \mathrm{mg}$ protein $/ \mathrm{ml}$ ) and $660 \mathrm{~nm}$ as an emission wavelength were chosen for these experiments.

\section{Formation of diffusion potential and its measurement}

Diffusion potential was created and measured by changing the ionic environment of the medium as described in the Materials AND Methods. Twenty $\mu 1$ of FSR $(7.5 \mathrm{mg}$ protein $/ \mathrm{ml})$ in $0.2 \mathrm{M} \mathrm{K}$-gluconate medium was diluted with $3 \mathrm{ml}$ of the medium containing $0.2 \mathrm{M}$ gluconate salts of $\mathrm{K}$ and $\mathrm{Na}, 2 \mu \mathrm{M}$ due, and 1 $\mu \mathrm{M}$ valinomycin. Valinomycin facilitates diffusion potential by increasing $\mathrm{K}^{+}$ permeability. When FSR was added, fluorescence intensity decreased transiently and reached the steady value which was approximately the same in all measurements (Fig. 2(a), the sensitivity of the fluorescence photometer was changed in each 


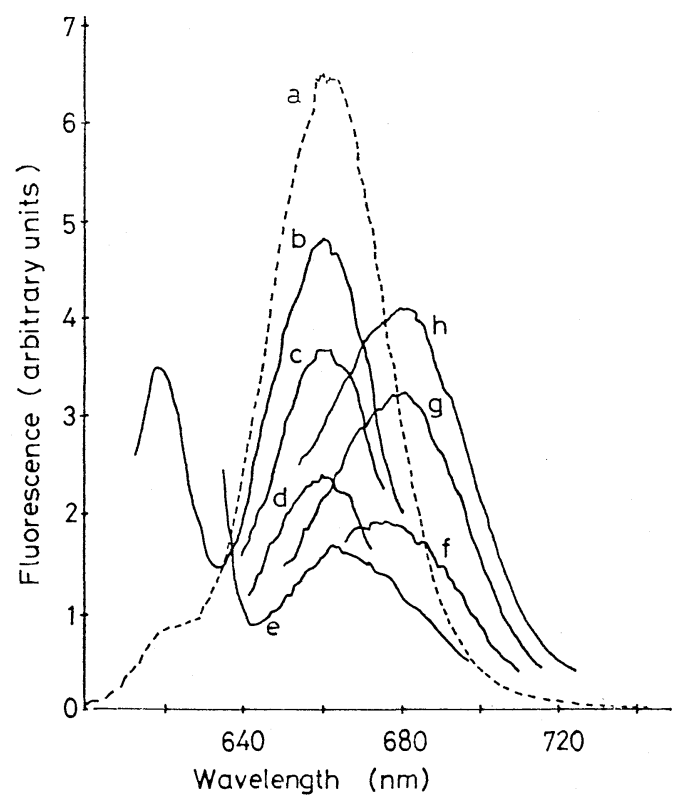

Fig. 1. Fluorescence emission spectra of $\operatorname{diS}_{-} \mathrm{C}_{3}-(5)$ in the absence and presence of FSR. FSR was suspended in the medium of $150 \mathrm{mM} \mathrm{KCl,} 20 \mathrm{mM}$ Tris-maleate ( $\mathrm{pH} \mathrm{6.8),} 2 \mu \mathrm{M}$ dye. FSR concentrations, (a) 0 , (b) 0.01 , (c) 0.025 , (d) 0.05 , (e) 0.10 , (f) 0.20 , (g) 0.50, or (h) $2.0 \mathrm{mg}$ protein $/ \mathrm{ml}$. Excitation, $620 \mathrm{~nm}$.

a

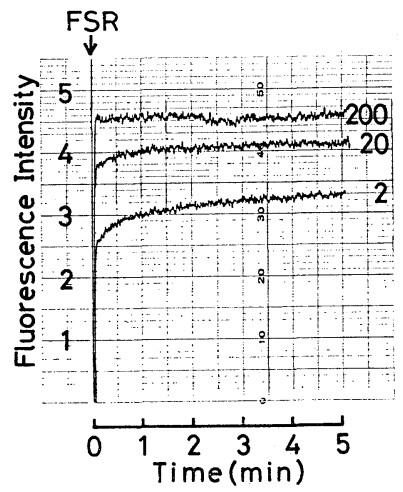

b

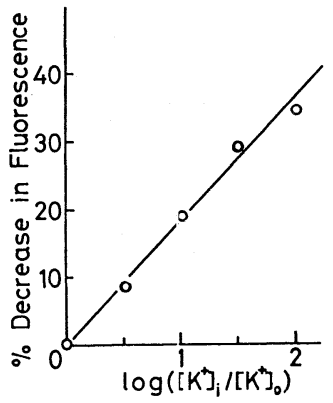

Fig. 2. Fluorescence intensity change induced by diffusion of: $\mathrm{K}^{+}$. (a) Fluorescence intensity change induced by diffusion of $\mathrm{K}^{+}$in the presence of valinomycin. Twenty $\mu \mathrm{l}$ of FSR ( $7.5 \mathrm{mg}$ protein $/ \mathrm{ml}$ in $0.2 \mathrm{M} \mathrm{K}$-gluconate) was diluted with $3 \mathrm{ml}$ of the medium containing $\mathrm{K}$ and $\mathrm{Na}$-gluconate in various ratios (total concentration, $0.2 \mathrm{M}$ ). The ratio of $\left[\mathrm{K}^{+}\right]_{\mathrm{i}}$ against $\left[\mathrm{K}^{+}\right]_{0}$ was changed from 1 to 100 . The $\left[\mathrm{K}^{+}\right]_{\mathrm{i}}$ is indicated in $\mathrm{mM}$ in the figure. (b) Representation of fluorescence intensity change as a function of $\log \left(\left[\mathrm{K}^{+}\right]_{\mathrm{i}} /\left[\mathrm{K}^{+}\right]_{\mathrm{o}}\right)$. Abscissa: $\log \left(\left[\mathrm{K}^{+}\right]_{\mathrm{i}} /\left[\mathrm{K}^{+}\right]_{\mathrm{o}}\right)$. Ordinate: percent change of fluorescence between 0 time and the steady level. 
experiment). Percent decrement of fluorescence intensity at time 0 compared with that at $5 \mathrm{~min}$ was plotted against $\log \left(\left[\mathrm{K}^{+}\right]_{\mathrm{i}} /\left[\mathrm{K}^{+}\right]_{\mathrm{o}}\right)$ (Fig. 2(b)). $\left[\mathrm{K}^{+}\right]_{\mathrm{i}}$, $\left[\mathrm{K}^{+}\right]_{\text {。 }}$ represent the $\mathrm{K}^{+}$concentrations inside and outside of FSR, respectively. A linear relationship between $\log \left(\left[\mathrm{K}^{+}\right]_{\mathrm{i}} /\left[\mathrm{K}^{+}\right]_{\mathrm{o}}\right)$ and fluorescence decrease was

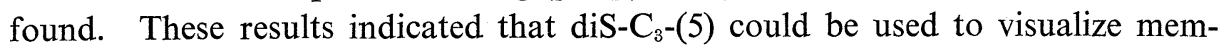
brane potential over a wide range, and that fluorescence intensity of diS- $\mathrm{C}_{3}-(5)$ increased when the potential changed toward the inside-positive direction. According to the Nernst equation, $1 \%$ change of fluorescence intensity should represent $3.13 \mathrm{mV}$.

Membrane potential formation by changing ionic composition of the medium

FSR ( $7.5 \mathrm{mg}$ protein $/ \mathrm{ml}$ ) was incubated overnight in $0.2 \mathrm{M} \mathrm{K}$-gluconate medium, and diluted quickly to $1 / 150$ with $0.2 \mathrm{M}$ various salt media. Membrane potential change induced by this procedure was monitored by following the change of fluorescence intensity. There was no change when FSR in K-gluconate was diluted with K-gluconate (Fig. 3(a)), which meant no membrane potential formation by dilution with the same buffer. When FSR was diluted with the medium of $0.2 \mathrm{M} \mathrm{KCl}$, fluorescence intensity decreased transiently and increased to a certain value in accordance with the redistribution of ions between the inside and outside

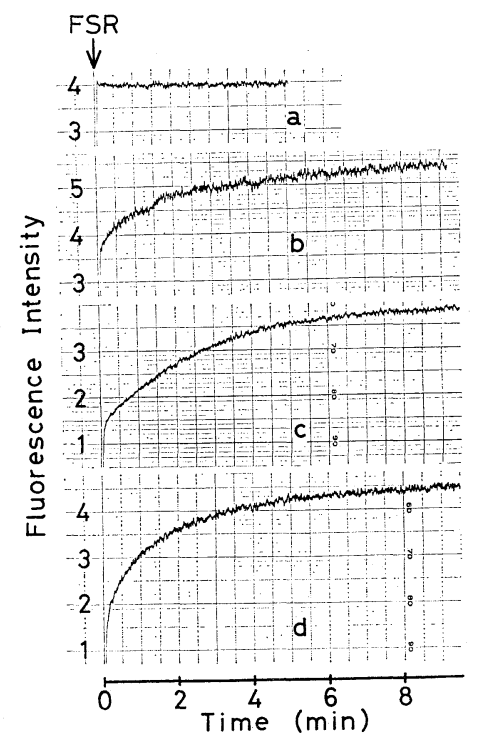

Fig. 3. Time course of fluorescence change of diS- $\mathrm{C}_{3}-(5)$. At the time indicated by the arrow, $20 \mu \mathrm{l}$ of FSR suspension $(7.5 \mathrm{mg}$ protein $/ \mathrm{ml})$ in $\mathrm{K}$-gluconate $(0.2 \mathrm{M})$ medium was added to $3 \mathrm{ml}$ of (a) $\mathrm{K}$-gluconate, (b) $\mathrm{KCl}$, (c) Tris-gluconate, (d) choline- $\mathrm{Cl}$ and mixed quickly. All reaction media contained $0.2 \mathrm{~m}$ respective salts, $10 \mathrm{~mm}$ Pipes-Tris ( $\mathrm{pH} 7.0$ ), $1 \mathrm{~mm} \mathrm{Mg}$-gluconate and $2 \mu \mathrm{M}$ dye. 
of the membrane (Fig. 3(b)). Fluorescence intensity decrement (about 30\%) obtained from the extrapolation of the curve (Fig. 3(b)) to time 0 represents inside-negative membrane potential formation due to $\mathrm{Cl}^{-}$influx, because $\mathrm{Cl}^{-}$is more permeable than gluconate ${ }^{-}$. Figures 3(c) and (d) indicate the results in the case of dilution from K-gluconate to Tris-gluconate or choline- $\mathrm{Cl}(0.2 \mathrm{M})$, respectively. Fluorescence intensity decreased about $60 \%$ at time 0 . These results imply that the inside-negative membrane potential is generated by the changing ionic composition of the medium. Changing the medium from Kgluconate to Tris-gluconate or choline- $\mathrm{Cl}$ created larger membrane potential change than from $\mathrm{K}$-gluconate to $\mathrm{KCl}$. These fluorescence changes also occurred to the same extent when $\mathrm{Ca}^{2+}$-preloaded FSR (see next paragraph) was used.

\section{$\mathrm{Ca}^{2+}$ release from FSR by changing ionic composition of the medium}

$\mathrm{Ca}^{2+}$ uptake was performed in $0.2 \mathrm{M} \mathrm{K}$-gluconate, $10 \mathrm{mM}$ Pipes-Tris ( $\mathrm{pH}$ 7.0), $1 \mathrm{mM} \mathrm{MgCl}_{2}, 0.1 \mathrm{mM}{ }^{45} \mathrm{CaCl}_{2}, 1 \mathrm{~mm}$ ATP and $0.05 \mathrm{mg}$ FSR protein $/ \mathrm{ml}$ for 3 min at $25^{\circ} \mathrm{C}$. $\mathrm{Ca}^{2+}$ uptake was terminated by filtration using a Millipore filter (HAWP, pore size; $0.45 \mu \mathrm{m}$ ). The amount of $\mathrm{Ca}^{2+}$ taken up by FSR was $147.3 \pm$ 11.2 nmols $\mathrm{Ca}^{2+} / \mathrm{mg}$ protein (mean \pm S.D.). FSR was then washed with washing solutions which contained $10 \mathrm{~mm}$ Pipes-Tris ( $\mathrm{pH}$ 7.0), $1 \mathrm{mM} \mathrm{MgCl}_{2}$ and different kinds of monovalent ions (Table 1). The amount of $\mathrm{Ca}^{2+}$ retained in FSR after washing was expressed as a percentage of that washed with K-gluconate solution. The results are shown in Table 1. When either Na-gluconate, Tris-gluconate, choline- $\mathrm{Cl}$, or Tris- $\mathrm{Cl}$ was used as a washing solution, no $\mathrm{Ca}^{2+}$ release from FSR was seen. However, when either $\mathrm{KCl}, \mathrm{NaCl}, \mathrm{LiCl}$, or $\mathrm{K}$-methanesulfonate medium was used, $\mathrm{Ca}^{2+}$ was released from FSR. It was revealed that not only permeable anion $\left(\mathrm{Cl}^{-}\right.$, methanesulfonate $\left.{ }^{-}\right)$, but permeable cation $\left(\mathrm{K}^{+}, \mathrm{Na}^{+}, \mathrm{Li}^{+}\right)$ was required for the release of $\mathrm{Ca}^{2+}$ from FSR. Methanesulfonate ${ }^{-}$is considered as an impermeable anion, however, it seems more permeable than gluconate ${ }^{-}$. On the other hand, when impermeable cation was used, no $\mathrm{Ca}^{2+}$ release occurred. $\mathrm{Ca}^{2+}$ release was inhibited by the addition of sucrose to washing solution (Table 1). These results suggest that there is no correlation between "depolarization" and $\mathrm{Ca}^{2+}$ release. $\mathrm{Ca}^{2+}$ release from FSR may be induced by an osmotic effect in this experimental system.

Table 1. $\mathrm{Ca}^{2+}$ release from FSR by ionic composition change of the medium.

\begin{tabular}{lclc}
\hline \multicolumn{1}{c}{$\begin{array}{l}\text { Washing } \\
\text { solution }\end{array}$} & $\begin{array}{c}\text { Remaining } \\
\mathrm{Ca}^{2+} \text { in FSR }(\%)\end{array}$ & \multicolumn{1}{c}{$\begin{array}{c}\text { Washing } \\
\text { solution }\end{array}$} & $\begin{array}{c}\text { Remaining } \\
\mathrm{Ca}^{2+} \text { in FSR }(\%)\end{array}$ \\
\hline $0.2 \mathrm{M} \mathrm{K-gluconate}$ & 100 & $0.2 \mathrm{M} \mathrm{KCl}$ & 5 \\
$0.2 \mathrm{M} \mathrm{Na-gluconate}$ & 95 & $0.2 \mathrm{M} \mathrm{NaCl}$ & 7 \\
$0.2 \mathrm{M}$ Tris-gluconate & 111 & $0.2 \mathrm{M} \mathrm{LiCl}$ & 9 \\
$0.2 \mathrm{M}$ choline-Cl & 95 & $0.2 \mathrm{M} \mathrm{K}-$ methanesulfonate & 14 \\
$0.2 \mathrm{M}$ Tris-Cl & 97 & $0.2 \mathrm{M} \mathrm{KCl}+0.3 \mathrm{M}$ sucrose & 116 \\
\hline
\end{tabular}




\section{Membrane potential change during $\mathrm{Ca}^{2+}$ uptake and release}

Time course of $\mathrm{Ca}^{2+}$ uptake upon addition of ATP is shown in Fig. 4(a). Neither dye nor ethanol (solvent of the dye) exhibited significant effect on $\mathrm{Ca}^{2+}$ uptake ability. Figure 4(b) indicates the fluorescence intensity change during $\mathrm{Ca}^{2+}$ fluxes in the medium containing $2 \mu \mathrm{M}$ dye. The fluorescence intensity increased according to the $\mathrm{Ca}^{2+}$ uptake, and the peak appeared before the amount of $\mathrm{Ca}^{2+}$ in FSR reached plateau level. By the application of $\mathrm{A} 23187, \mathrm{Ca}^{2+}$ in the FSR was rapidly released (Fig. 4(a)) and simultaneously, the fluorescence

\section{a}
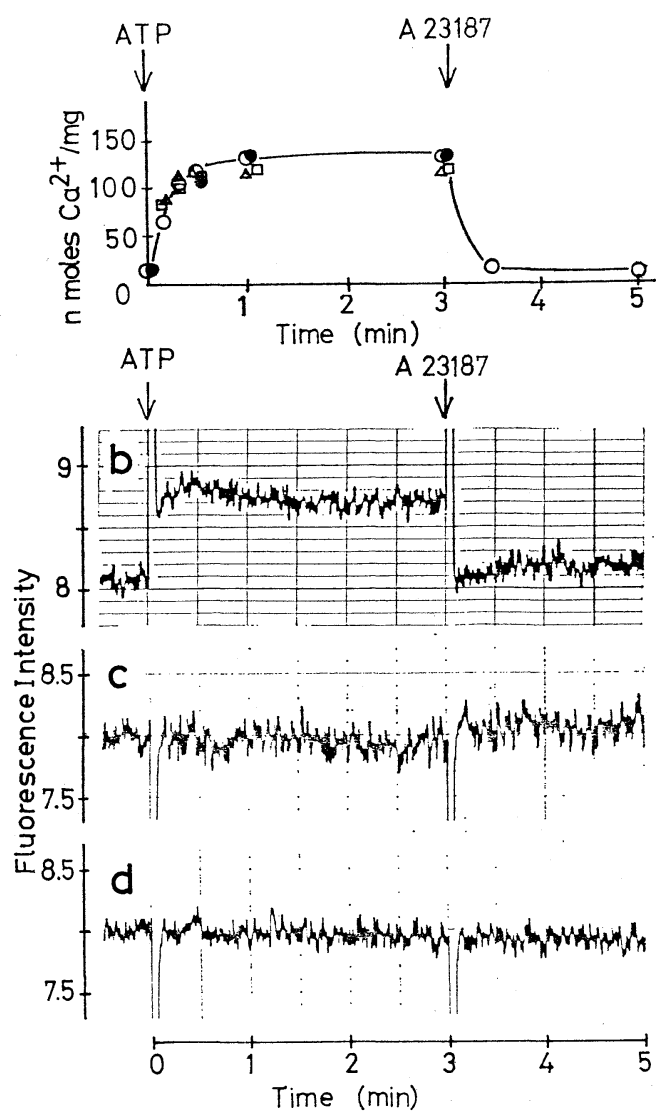

Fig. 4. $\mathrm{Ca}^{2+}$ uptake and membrane potential. The reaction was started by the addition of ATP (first arrow), and $\mathrm{Ca}^{2+}$ was released by the application of A23187 after 3 min (second arrow). (a) Time course of $\mathrm{Ca}^{2+}$ fluxes and the effect of dye and ethanol. Reaction mixture contained $0(\bigcirc), 1(\triangle), 2(\square) \mu \mathrm{M}$ dye, or solvent of dye, $0.66 \% \mathrm{EtOH}$ (๑). $\mathrm{Ca}^{2+}$ in FSR was measured as described in Materials AND Methods. (b) Time dependence of fluorescence intensity during $\mathrm{Ca}^{2+}$ fluxes. (c) Fluorescence intensity change in the presence of $10 \mathrm{~mm}$ EGTA. (d) Fluorescence intensity change in the presence of $2 \mathrm{~mm}$ verapamil. 


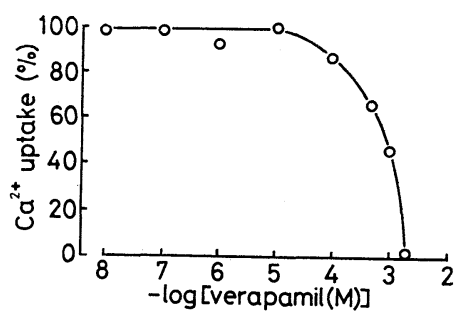

Fig. 5. Effect of verapamil on $\mathrm{Ca}^{2+}$ uptake by FSR. Reaction was carried out as shown in Fig. 4(a). The amounts of $\mathrm{Ca}^{2+}$ taken up by FSR are represented as percentages of the control (without verapamil).

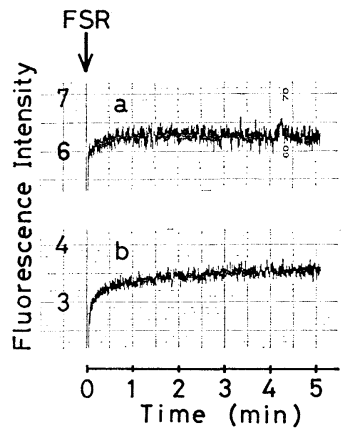

Fig. 6. Effect of verapamil on fluorescence intensity change induced by diffusion of $\mathrm{K}^{+}$. Reaction was carried out as described in Fig. 2(a). FSR in $200 \mathrm{~mm} \mathrm{~K}$-gluconate medium was diluted with $2 \mathrm{~mm} \mathrm{~K}$-gluconate and $198 \mathrm{~mm}$ Na-gluconate medium at the time indicated by the arrow. (a) In the presence of $2 \mathrm{~mm}$ verapamil. (b) Control (no verapamil).

intensity decreased to the initial level (Fig. 4(b)). No fluorescence intensity change was observed in $\mathrm{Ca}^{2+}$-free medium (10 mm EGTA) as shown in Fig. 4(c). Verapamil, a drug known as a $\mathrm{Ca}^{2+}$ antagonist, inhibitec ATP-dependent $\mathrm{Ca}^{2+}$ uptake by FSR (Fig. (5)). In the presence of $2 \mathrm{~mm}$ verapamil in the reaction medium $\left(0.1 \mathrm{~mm} \mathrm{CaCl}_{2}\right)$ neither $\mathrm{Ca}^{2+}$ uptake nor fluorescence intensity change occurred upon addition of ATP (Fig. 4(d)), although $2 \mathrm{~mm}$ verapamil had a small effect on fluorescence intensity change (Fig. 6). Thus, fluorescence intensity change was always associated with the $\mathrm{Ca}^{2+}$ fluxes across the FSR membrane.

It is concluded that positive-inside membrane potential is built up during $\mathrm{Ca}^{2+}$ uptake and sustained until $\mathrm{Ca}^{2+}$ release occurs, although it is unlikely that fluorescence intensity simply reflects the amount of $\mathrm{Ca}^{2+}$ in FSR.

Effects of valinomycin and nigericin, and the replacement of $\mathrm{Cl}^{-}$with gluconate ${ }^{-}$, on the fluorescence intensity changes during $\mathrm{Ca}^{2+}$ uptake and release

To study the movement of $\mathrm{K}^{+}$and $\mathrm{Cl}^{-}$during $\mathrm{Ca}^{2+}$ uptake, the effects of 


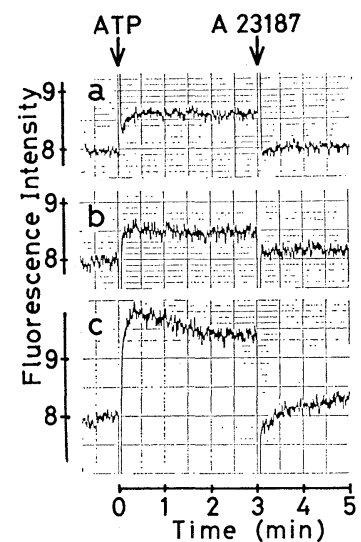

Fig. 7. Effects of valinomycin, nigericin, and replacement of $\mathrm{Cl}^{-}$with gluconate ${ }^{-}$on fluorescence intensity change associated with $\mathrm{Ca}^{2+}$ fluxes. In the presence of (a) $1.0 \mu \mathrm{M}$ valinomycin, (b) $0.1 \mu \mathrm{M}$ nigericin and (c) $\mathrm{Cl}^{-}$substitution with gluconate ${ }^{-}$. Conditions were the same as in Figs. 4(b)-(d).

valinomycin and nigericin, and the replacement of $\mathrm{Cl}^{-}$with gluconate- were examined. Presence of $1 \mu \mathrm{M}$ valinomycin or $0.1 \mu \mathrm{M}$ nigericin in the reaction medium containing $\mathrm{KCl}$ affected the fluorescence intensity change due to $\mathrm{Ca}^{2+}$ uptake as shown in Fig. 7. The peak which was found in Fig. 4(b) (control) was not observed and the intensity was reduced to a small extent in the presence of valinomycin or nigericin (Fig. 7(a), (b)). The amount of $\mathrm{Ca}^{2+}$ taken up by FSR was slightly enhanced (about $6.5 \%$ ) in the presence of $1 \mu \mathrm{M}$ valinomycin. This coincides with the results reported by ZIMNIAK and RACKER (1978). This phenomena can be understood by supposing that the $\mathrm{Ca}^{2+}$ uptake is accompanied by rapid $\mathrm{K}^{+}$efflux and that the potential created by $\mathrm{Ca}^{2+}$ uptake is partially compensated. The replacement of $\mathrm{Cl}^{-}$with gluconate ${ }^{-}$enhanced and prolonged the fluorescence intensity change due to $\mathrm{Ca}^{2+}$ uptake markedly (Fig. 7(c)). Aslo, gluconate ${ }^{-}$substitution enhanced the $\mathrm{Ca}^{2+}$ uptake ability of FSR (in $\mathrm{KCl}, 110.0 \pm$ 7.6; in K-gluconate, $142.8 \pm 17.8 \mathrm{nmols} \mathrm{Ca}^{2+} / \mathrm{mg}$ protein (mean \pm S.D.)). This means $\mathrm{Ca}^{2+}$ uptake is accompanied by $\mathrm{Cl}^{-}$influx in $\mathrm{KCl}$ medium and that thereby $\mathrm{Ca}^{2+}$ uptake and membrane potential change may be suppressed. Presence of valinomycin or nigericin had no noticeable effect on fluorescence intensity change in the $\mathrm{Cl}^{-}$-replaced medium.

\section{DISCUSSION}

To understand the excitation-contration coupling mechanism in skeletal muscle, it is essential to know whether membrane potential change of SR is associated with $\mathrm{Ca}^{2+}$ uptake and release. It has been shown in skinned muscle fibers and isolated sarcoplasmic reticulum that $\mathrm{Ca}^{2+}$ could be released from SR 
by changing anion in the medium from methanesulfonate- to $\mathrm{Cl}^{-}$. In this case influx of $\mathrm{Cl}^{-}$causes "depolarization" of the membrane of SR which may trigger $\mathrm{Ca}^{2+}$ release. However, there is no direct method for measurement of SR membrane potential.

We investigated here the relationship between $\mathrm{Ca}^{2+}$ fluxes in FSR and its membrane potential change employing optical probe. Cyanine dye (SIMs et al., 1974) which was used here seemed to be suitable for this study because it gave large fluorescence intensity change depending on the ionic composition change of the medium in the presence of FSR. Since $\mathrm{Ca}^{2+}$ or ATP itself does not affect the fluorescence, the intensity change shown here reflects the membrane potential change, although there still may be a possibility that the responses originate from other than membrane potential (BEELER et al., 1979).

The ionic composition change from K-gluconate to Tris-gluconate caused a large inside-negative membrane potential (Fig. 3(c)) probably generated by $\mathrm{K}^{+}$ efflux. But no $\mathrm{Ca}^{2+}$ release from FSR occurred (Table 1). On the other hand, the change from $\mathrm{K}$-gluconate to $\mathrm{KCl}$ caused a large amount of $\mathrm{Ca}^{2+}$ release from FSR with small membrane potential change. Addition of sucrose to $\mathrm{KCl}$ washing solution inhibited the release of $\mathrm{Ca}^{2+}$ from FSR (Table 1). These results suggest that there is no correlation between "depolarization" and $\mathrm{Ca}^{2+}$ release from FSR. Furthermore, both permeable anion and cation were required to induce $\mathrm{Ca}^{2+}$ release. These results indicate that $\mathrm{Ca}^{2+}$ release from FSR by the ionic environment change of the medium is due to the osmotic effect. It was reported that $\mathrm{Ca}^{2+}$ release could be induced by cation exchange in skinned muscle fibers (NAKAJIMA and ENDO, 1973), however, this was never observed in FSR (Table 1).

Fluorescence study during $\mathrm{Ca}^{2+}$ uptake indicates that $\mathrm{Ca}^{2+}$ uptake is associated with the build-up of the inside-positive membrane potential of about $30 \mathrm{mV}$ (Figs. 2(a) and 4(b)). The cause of membrane potential may be the electrogenic $\mathrm{Ca}^{2+}$ pump, together with asymmetrical distribution of permeable ions associated with $\mathrm{Ca}^{2+}$ uptake for the partial compensation of the charge. This potential disappears on the release of $\mathrm{Ca}^{2+}$ (Fig. 4). Moreover, the addition of valinomycin or nigericin, and the replacement of $\mathrm{Cl}^{-}$with gluconate- affects the fluorescence intensity change (Fig. 7). These facts suggest that $\mathrm{Ca}^{2+}$ uptake was accompanied by $\mathrm{K}^{+}$efflux and/or $\mathrm{Cl}^{-}$influx, resulting in partial compensation of the electrogenic potential created by $\mathrm{Ca}^{2+}$ accumulation. There was a tendency that in the presence of a less-permeable anion in the medium, both formation of membrane potential and $\mathrm{Ca}^{2+}$ uptake by FSR were potentiated. $\mathrm{Cl}^{-}$influx associated with $\mathrm{Ca}^{2+}$ uptake may inhibit further $\mathrm{Ca}^{2+}$ uptake by increasing osmolarity inside the FSR. Valinomycin facilitates $\mathrm{Ca}^{2+}$ uptake ability of FSR probably by increasing $\mathrm{K}^{+}$permeability which favors the compensation of the charge and osmolarity change due to $\mathrm{Ca}^{2+}$ uptake. However, fluorescence intensity change was depressed slightly by valinomycin (Figs. 4 and 7). These facts suggest that the fluorescence intensity is not a simple reflection of the amount 
of $\mathrm{Ca}^{2+}$ in FSR.

The evidence shown here indicates that although inside-positive membrane potential is generated due to the $\mathrm{Ca}^{2+}$ uptake, depolarization of SR membrane does not cause $\mathrm{Ca}^{2+}$ release. However, this does not prove that the depolarization-induced $\mathrm{Ca}^{2+}$ release mechanism is never operated in intact muscle. As well known, there are differences in nature of internal membrane of skeletal muscle depending on location, such as longitudinal, transverse and terminal cisternae (MEISSNER, 1975; WINEGRAD, 1968). Since FSR used in this preparation contained various components, further investigation using different parts of $\mathrm{SR}$ is necessary to understand the excitation-contraction coupling mechanism.

The authors wish to thank Professor S. Iwata of Meijo Univ. for his valuable suggestions. This study was partially supported by grant $80-01-25$ from the National Center for Nervous, Mental and Muscular Disorders of the Ministry of Health and Welfare, Japan.

\section{REFERENCES}

Åkerman, K. E. O. and WolfF, C. H. J. (1979) Charge transfer during $\mathrm{Ca}^{2+}$ uptake by rabbit skeletal muscle sarcoplasmic reticulum vesicles as measured with oxanol VI. FEBS Lett., 100: 291-295.

Bastian, J. and NaKajima, S. (1974) Action potential in the transverse tubules and its role in the activation of skeletal muscle. J. Gen. Physiol., 63: 257-278.

Beeler, T., Russell, J. T., and Martonosi, A. (1979) Optical probe responses on sarcoplasmic reticulum: Oxacarbocyanines as probes of membrane potential. Eur. J. Biochem., 95: 579-591.

Caputo, C. (1978) Excitation and contraction processes in muscle. Annu. Rev. Biophys. Bioeng., 7: 63-83.

Endo, M. (1977) Calcium release from the sarcoplasmic reticulum. Physiol. Rev., 57: 71-108.

Ford, L. E. and Podolsky, R. J. (1970) Regenerative calcium release within muscle cells. Science, 167: 58-59.

IWATA, S. and HorIUCHI, M. (1980) Studies on experimental cataracts induced by ionophoresin vitro effects of nigericin and valinomycin on the lenses in mice. Exp. Eye Res., 31 : 543-551.

KasAi, M. and MiYamoto, H. (1973) Depolarization induced calcium release from sarcoplasmic reticulum membrane fragments by changing ionic environment. FEBS Lett., 34: 299-301.

KaSAI, M. and MiYамото, H. (1976) Depolarization-induced calcium release from sarcoplasmic reticulum fragments. I. Release of calcium taken up upon using ATP. J. Biochem., 79: 1053-1066.

Meissner, G. (1975) Isolation and characterization of two types of sarcoplasmic reticulum vesicles. Biochim. Biophys. Acta, 389: 51-68.

Meissner, G. and McKinley, D. (1976) Permeability of sarcoplasmic reticulum membrane. The effect of changed ionic environments on $\mathrm{Ca}^{2+}$ release. J. Membr. Biol., 30: 79-98.

NAKAJIMA, Y. and ENDO, M. (1973) Release of calcium induced by 'depolarisation' of the sarcoplasmic reticulum membrane. Nature (New Biol.), 246: 216-218.

OHNishi, S. T. (1979) A method for studying the depolarization-induced calcium ion release from fragmented sarcoplasmic reticulum. Biochim. Biophys. Acta, 587: 121-128.

Sims, P. J., WAgGoner, A. S., WANG, C. H., and Hoffman, J. F. (1974) Studies on the mechanism by which cyanine dyes measure membrane potential in red blood cells and phos-

Vol. 31, No: 1, 1981 
phatidylcholine vesicles. Biochemistry, 13: 3315-3330.

WINEGRAD, S. (1968) Intracellular calcium movements of frog skeletal muscle during recovery from tetanus. J. Gen. Physiol., 51: 65-83.

ZIMNIAK, P. and RACKER, E. (1978) Electrogenicity of $\mathrm{Ca}^{2+}$ transport catalyzed by the $\mathrm{Ca}^{2+}$ ATPase from sarcoplasmic reticulum. J. Biol. Chem., 253: 4631-4637. 